[EDITORIAL]

\title{
Gearing up at the Review
}

Things have been going well for Drug and Alcohol Review. Paper submissions have gone up from around 100 to more than 300 per year over the past 10 years. So too has our Impact Factor, now over 2.4, highlighting the strong position the journal now holds among a growing number of international journals in the alcohol and other drugs field. We hope that you, as readers and consumers of the Review's content, have found the work of our contributors as stimulating, insightful and useful as we have.

This growth in the journal carries implications for change. The Review's current organisation and procedures no longer fit what the journal has become. The increasing demand to publish in the journal has led to more papers than we can publish within our page limit. Currently 'Early View', where in press articles are de-facto published but await a journal issue, holds 74 accepted papers. Rejection rates are already high. To increase the rejection rate further would mean rejecting good work for lack of space. It would also undermine our aim to balance the readership needs of our Australasian and our global audiences, and also our intent to publish innovative work that pushes our thinking forward both from well-established research centres and from new voices from the Asia Pacific and other regions. Furthermore, the rapid growth of submissions has challenged our current decision-making processes.

With the agreement of the APSAD Council, and after discussion by the Editorial Board and at a strategic planning meeting, we are therefore instituting some substantial changes.

To accommodate the growing demand for publication in the journal, we are increasing the number of pages published each year. Effective from 2017, this figure will go up by about $10 \%$ with the introduction of an additional issue, taking the journal from six to seven issues per year.

To maintain consistency in the editorial process we are introducing a group of Senior Editors to the journal. This tier of Senior Editors will help manage the increasing number of submissions by identifying papers of high priority. They will oversee the editorial and decision-making process of all reviewed manuscripts to ensure consistency in the journal's standards. It will be the responsibility of the Senior Editor to make a final decision on whether a paper is published.

The cadre of Deputy Editors on the journal's Editorial Board will remain in place and indeed increase, carrying on the crucial work of managing the review processes for papers - finding and persuading appropriate reviewers to provide critical appraisal of submitted manuscripts, synthesising this feedback, and making a summative recommendation to the Senior Editor, drawing on their expertise in the field.

This is the author manuscript accepted for publication and has undergone full peer review but has not been through the copyediting, typesetting, pagination and proofreading process, which may lead to differences between this version and the Version of Record. Please cite this article as doi: $10.1111 /$ dar.12577

This article is protected by copyright. All rights reserved. 
We will also appoint qualitative and quantitative Methods Editors to support members of the Editorial Board in evaluating the methodological strength of submissions.

We also expect to identify a Scientific Advisory Board to provide advice on the journal's strategic direction and support the review of submitted manuscripts.

The Executive Editor and Editor-in-Chief will continue to provide oversight to all editorial and journal processes, with the Executive Editor managing decisions on whether submissions meet minimum criteria to go into the review process, and the Editor-in-Chief maintaining overall responsibility for the editing of the journal.

From the point of view of authors of papers, these changes should not be very visible. The Review does reasonably well in getting from the submission of a paper to a decision on whether to accept it, and our aim is to modestly improve the timing in our performance there. Once accepted, Wiley/Blackwell moves quite fast to copy-edit and typeset the paper, getting it onto 'Early View' so that it is has a DOI, and is published on the web and citable. With the increase in pages, we expect the lag till final page-number publication to shorten. More importantly, the increase means that the Review will be in a position to increase at least modestly its contribution to the advancement of science in our field.

The strategic changes will allow us to meet the challenges of the coming decade by ensuring that we efficiently manage the increasingly large number of submissions we receive while continuing to strengthen the quality and the standing of the journal in the field. We look forward to working with authors, reviewers, and other members of the Editorial Board in gearing up the Review as the field advances.

Robin Room, Editor-in-Chief

Paul Dietze, Executive Editor

Rebecca McKetin, former Executive Editor

This article is protected by copyright. All rights reserved. 


\section{University Library}

\section{- M M I E R R A A gateway to Melbourne's research publications}

Minerva Access is the Institutional Repository of The University of Melbourne

Author/s:

Room, R;Dietze, P;McKetin, R

Title:

Gearing up at the Review.

Date:

2017-07

Citation:

Room, R., Dietze, P. \& McKetin, R. (2017). Gearing up at the Review.. Drug Alcohol Rev, 36 (4), pp.441-. https://doi.org/10.1111/dar.12577.

Persistent Link:

http://hdl.handle.net/11343/293139 